\title{
Web Use for Symptom Appraisal of Physical Health Conditions: A Systematic Review
}

Julia Mueller $^{1,2,3}$, MSc; Caroline Jay ${ }^{3}, \mathrm{PhD}$; Simon Harper ${ }^{3}$, PhD; Alan Davies ${ }^{3}$, BSc; Julio Vega ${ }^{3}$, MSc; Chris Todd ${ }^{1,2}$, $\mathrm{PhD}$

\footnotetext{
${ }^{1}$ School of Health Sciences, University of Manchester, Manchester, United Kingdom

${ }^{2}$ Manchester Academic Health Science Centre, Manchester, United Kingdom

${ }^{3}$ School of Computer Science, University of Manchester, Manchester, United Kingdom
}

\section{Corresponding Author:}

Julia Mueller, MSc

School of Health Sciences

University of Manchester

Kilburn Building, LF1

Oxford Road

Manchester, M13 9PL

United Kingdom

Phone: 441612756239

Fax: 441613067894

Email: julia.mueller@manchester.ac.uk

\section{Abstract}

Background: The Web has become an important information source for appraising symptoms. We need to understand the role it currently plays in help seeking and symptom evaluation to leverage its potential to support health care delivery.

Objective: The aim was to systematically review the literature currently available on Web use for symptom appraisal.

Methods: We searched PubMed, EMBASE, PsycINFO, ACM Digital Library, SCOPUS, and Web of Science for any empirical studies that addressed the use of the Web by lay people to evaluate symptoms for physical conditions. Articles were excluded if they did not meet minimum quality criteria. Study findings were synthesized using a thematic approach.

Results: A total of 32 studies were included. Study designs included cross-sectional surveys, qualitative studies, experimental studies, and studies involving website/search engine usage data. Approximately $35 \%$ of adults engage in Web use for symptom appraisal, but this proportion varies between $23 \%$ and $75 \%$ depending on sociodemographic and disease-related factors. Most searches were symptom-based rather than condition-based. Users viewed only the top search results and interacted more with results that mentioned serious conditions. Web use for symptom appraisal appears to impact on the decision to present to health services, communication with health professionals, and anxiety.

Conclusions: Web use for symptom appraisal has the potential to influence the timing of help seeking for symptoms and the communication between patients and health care professionals during consultations. However, studies lack suitable comparison groups as well as follow-up of participants over time to determine whether Web use results in health care utilization and diagnosis. Future research should involve longitudinal follow-up so that we can weigh the benefits of Web use for symptom appraisal (eg, reductions in delays to diagnosis) against the disadvantages (eg, unnecessary anxiety and health care use) and relate these to health care costs.

(J Med Internet Res 2017;19(6):e202) doi: 10.2196/jmir.6755

\section{KEYWORDS}

Online health information; health information seeking; Internet; symptom appraisal; Web search; search strategies

\section{Introduction}

The Web has become an important resource for lay information about health, with almost three-quarters of the population in developed countries accessing the Web to research health topics $[1,2]$. The Web is accessed to obtain information on general health topics, such as weight management, and by patients to obtain information on their diagnosed condition $[3,4]$. Moreover, 
the Web is accessed to assess and evaluate symptoms and their causes [1].

The way the Web is used by patients who have obtained a specific diagnosis from a health care professional is likely to differ from the way it is used in the absence of a professional diagnosis when appraising symptoms. Postdiagnosis, individuals have specific medical terms they can use as search terms. Most focus their Web search on treatment options, illness management, and prognosis $[3,4]$. When appraising symptoms with the aim of diagnosing them, on the other hand, most individuals have only symptoms and lay medical knowledge to guide their search, and symptoms are sometimes vague and difficult to describe.

Web use for symptom appraisal may have important implications, although it is unclear whether it plays a beneficial or detrimental role in health care delivery. For example, some evidence suggests it could lead to unnecessary anxiety about health and increase use of health service resources [5]. Other findings imply it could enhance patient empowerment and help patients prepare for consultations [6]. Thus, Web use for symptom appraisal may lead to either wasting or more efficient use of resources. For example, Web use for symptom appraisal may cause anxiety about health by making individuals falsely believe they have a serious condition when they do not. On the other hand, it may encourage people with warning signs to present to health services, promoting earlier diagnosis. It could also falsely reassure people that symptoms are not serious, thus preventing earlier diagnosis. This is particularly important for potentially life-threatening or debilitating conditions, which are easier to treat when detected early, such as cancer [7], heart disease [8], or glaucoma [9]. Understanding Web use for symptom appraisal is also relevant for less serious conditions, such as a common cold, because it could lead people with mild symptoms to present to health services when this is not necessary or it could help people identify the symptoms that can be treated at home. As these examples highlight, Web use for symptom appraisal may have important implications for health care utilization.

To leverage the potential for reducing strain on health care resources and promoting earlier diagnosis, we need to understand the current role of the Web in help seeking and symptom evaluation, and the strategies people use to access information, taking differing contexts into account. Because these questions cannot be addressed in a single study, a systematic review is required, involving a thorough and comprehensive search of the literature, critical appraisal of individual studies, and extraction and synthesis of relevant findings.

This systematic review addresses the following five review questions:

1. What proportion of different populations (eg, general, specific disease, or demographic groups) use the Web to appraise symptoms?

2. Which symptoms are likely to be researched online?

3. How is Web use for symptom appraisal conducted (search strategies)?
4. What are the behavioral consequences of Web use for symptom appraisal?

5. What are the emotional consequences of Web use for symptom appraisal?

\section{Methods}

A protocol was developed by the research team based on the review questions and an initial broad search of the available literature, using the Centre for Reviews and Dissemination's guidance for undertaking reviews in health care [10] and the Preferred Reporting Items for Systematic Reviews and Meta-Analyses (PRISMA) statement [11].

\section{Eligibility Criteria}

\section{Study Focus}

We included studies that addressed use of the Web to appraise symptoms (ie, to research symptoms and their potential causes). This could include both actual symptoms and symptoms in fictional scenarios. This did not have to be the primary focus of the study; some reference to Web use for symptom appraisal was sufficient. If studies examined health-related Web use in general, they were screened during full-text review and excluded if no specific reference to symptom appraisal was made. Studies that analyzed anonymous logs were included if they examined symptom-related searches. We included only studies that focused on human behavior; studies that evaluated the performance of Web-based tools were excluded.

\section{Populations}

Studies on Web use for symptom appraisal of any physical health conditions were included. Studies examining mental health/psychiatric conditions were excluded to focus the scope of the review. Studies on Web use by health professionals were excluded. Studies from any country were included, as long as the publication was written in English.

\section{Study Design}

Our initial scoping suggested a scarcity of research in this area, thus we did not limit included studies to any particular design. Nonempirical studies (eg, theoretical papers and literature reviews) were excluded.

\section{Publication Types}

Full paper, English-language publications were included, regardless of the original language of the research.

\section{Information Sources}

We searched PubMed, EMBASE, PsycINFO, ACM Digital Library, SCOPUS, and Web of Science for relevant publications up to September 30, 2016. To minimize publication bias, grey literature was explored by searching OpenGrey, an open-access database containing more than 700,000 bibliographical references of grey literature. We also searched the British Library Integrated catalog, which contains reports, conference abstracts, and theses. Finally, authors in the field were contacted to inquire about any unpublished material, if two or more of their papers were among the included studies, or if their paper was judged as particularly relevant to the review (eg, if 
examining Web use for symptom appraisal was the primary focus of the study).

\section{Search}

The terms Internet, Web, online, search engine, Google, help seeking, health information seeking, symptom, and diagnosis were entered into the databases (note Google was used as a search term because this is by far the most widely used search engine worldwide [12]). An example search strategy is provided in Multimedia Appendix 1.

\section{Study Selection}

The study selection process followed the guidelines provided in the PRISMA statement [11]. Search terms were entered into the databases and all returned studies were imported into a single Mendeley file. Three independent reviewers assessed the studies for eligibility. Studies were first screened by titles and abstracts. Selected studies were then screened for inclusion by reading full texts. Reference lists of included studies were handsearched for further eligible studies. We also handsearched journals if they contained two or more articles included in this review or if the general journal topic area was particularly relevant to the review, to ensure inclusion of studies not yet loaded on electronic databases. Any discrepancies between the reviewers were discussed until consensus was reached.

\section{Data Collection Process and Data Items}

From each study, any information regarding use of the Web for symptom appraisal was extracted, as well as details on study design, procedure, population, sampling method, entry and inclusion criteria for study participants, sample size, measures, and details of analysis methods (data extraction sheet in Multimedia Appendix 2).

\section{Quality Appraisal}

A quality appraisal of selected articles was conducted based on five criteria designed for reviews incorporating mixed study designs [13] (Multimedia Appendix 3). Quality appraisal involved two stages. First, articles were assessed for inclusion in the review using a relatively liberal threshold; articles were scored eligible if they addressed each criterion at least minimally. Criteria were then applied more rigorously using a three-point scoring system (low/medium/high; see Multimedia Appendix 3) and main limitations of each study were identified. This assessment was used to critically appraise studies during synthesis of the findings.

\section{Synthesis of Results}

The extracted data were synthesized using Thematic Analysis, which has been identified as one of the main approaches used to review and synthesize qualitative and quantitative evidence $[14,15]$. Our analysis involved the following steps [16]:

1. Data familiarization: familiarization with the data was achieved by reading all included studies several times and extracting the relevant information into the data extraction sheets.

2. A priori grouping: data from the data extraction sheets were grouped according to the review question they pertained to and summarized in a matrix. Studies were entered into the rows of the matrix, whereas study characteristics, limitations, and review questions were entered into the columns. This matrix enabled us to compare the findings of different studies pertaining to the same review question, taking methodological aspects into account (example matrix shown in Multimedia Appendix 4). This method was adapted from Framework Analysis, which is a specific form of Thematic Analysis [17].

3. Generation of initial codes: the data were initially coded using semantic codes within the NVivo10 environment, using the matrix to compare results across studies.

4. Searching for themes: once all data extracts were coded, codes were sorted into broader, more conceptual categories to create themes.

5. Reviewing themes: finally, we reviewed the data extracts the themes related to, to determine whether the created themes satisfactorily captured the raw data.

For quantitative studies reporting proportions without confidence intervals, $95 \%$ confidence intervals were computed using the asymptotic (Wald) method based on a normal approximation [18] to facilitate comparisons between studies.

\section{Results}

\section{Study Selection}

Thirty-two studies were identified as eligible for inclusion in the review. The search process is illustrated in Figure 1. The grey literature search yielded no further inclusions. The Journal of Medical Internet Research, the Journal of Health Communication, Telemedicine and e-Health, and the Journal of the American Medical Informatics Association were handsearched, resulting in 15 full-text assessments and two further inclusions. Four authors were contacted to enquire about unpublished material. We received one reply, concerning an article we had already identified. 
Figure 1. PRISMA diagram for the study identification process.

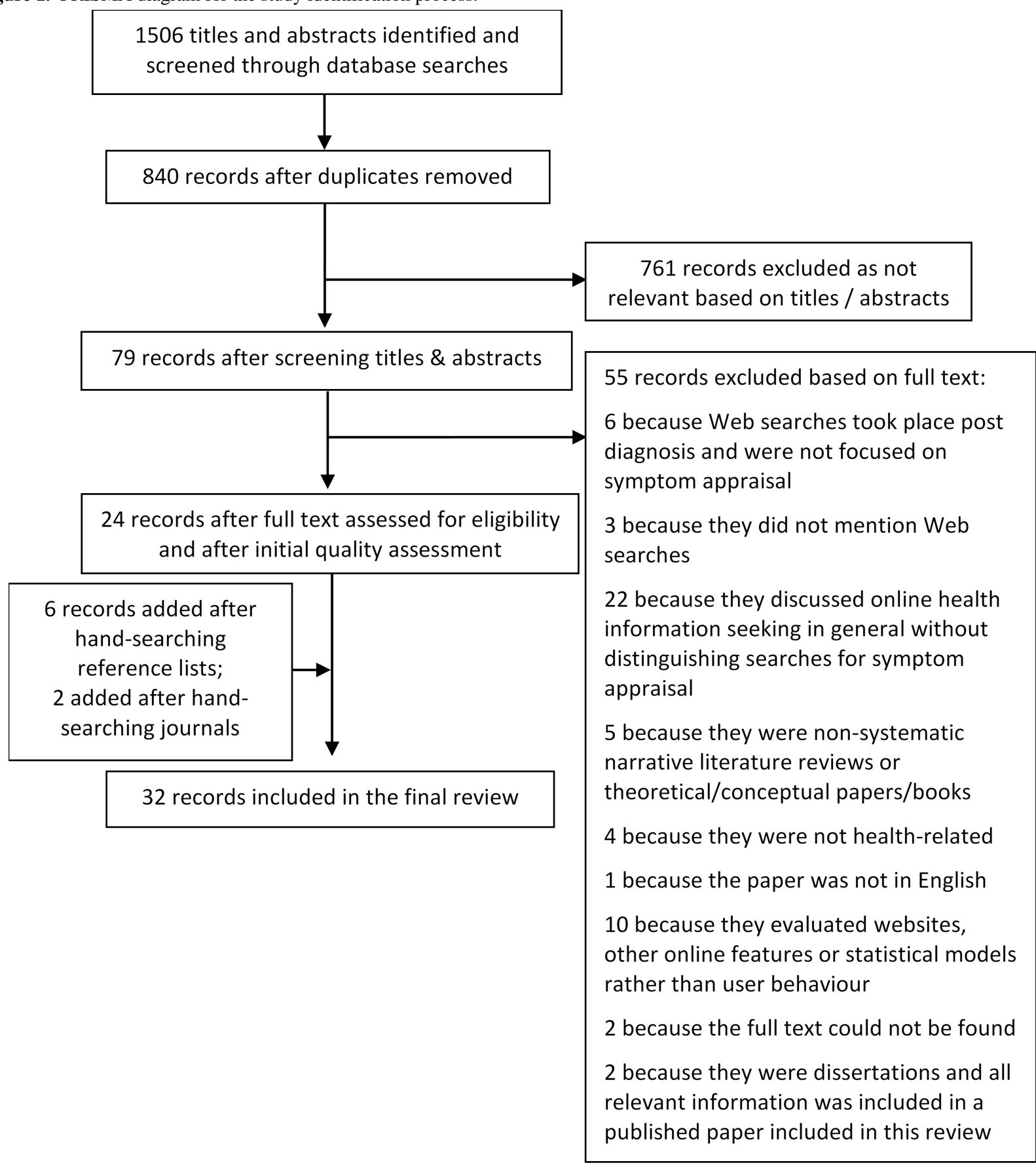

\section{Study Characteristics}

Tables 1-3 provide an overview of study characteristics. Study designs included cross-sectional surveys $(n=10$, two of these with embedded qualitative interview studies, one with an embedded observational study), qualitative interview and focus group studies $(n=4)$, experimental studies $(n=7)$, two studies evaluating questions posed by users to a health website $(n=2)$, a study evaluating clicks on a specific health website $(n=1)$, and studies involving the analysis of log data from search engines $(n=8)$. Two of these combined a log-based approach with a survey. Most studies were conducted in the United States $(n=25)$. 
Table 1. Study design and aim of the studies included in the review $(\mathrm{N}=32)$.

\begin{tabular}{ll}
\hline Author, date & Study design \\
\hline Attfield et al, 2006 [6] & $\begin{array}{l}\text { Qualitative interview study; cross-section- } \\
\text { al }\end{array}$ \\
Briet et al, 2014 [19] & $\begin{array}{l}\text { Quantitative; cross-sectional analysis of } \\
\text { website queries }\end{array}$ \\
Cartrightet et al, 2011 [20] & Longitudinal log-based study \\
Chin, 2009 [21] & $\begin{array}{l}\text { Experimental between subjects design: } \\
2 \times 2 \text { (ill-well-defined tasks, younger-older } \\
\text { users) }\end{array}$ \\
Chin \& Fu, 2010 [22] & $\begin{array}{l}\text { Experimental between subjects design: } \\
2 \times 2 \times 2 \text { (older-younger adults, parts-sys- } \\
\text { tems interface, parts-system task) }\end{array}$
\end{tabular}

Cooper et al, 2013 [23]

Cumming et al, 2010 [24]

De Choudhury et al, 2014 [25] Cross-sectional survey study (quantitative + qualitative data) + longitudinal logbased study

Fiksdal et al, 2014 [26]

Fox \& Duggan, 2013 [1]

Hay et al, 2008 [27]

Keselman et al, 2008 [28]

Lauckner \& Hsieh, 2013 [29]

Luger, 2014 [30]

Medlock et al, 2015 [31]

Morgan et al, 2014 [32]

Mueller et al, 2016 [33]

Norr et al, 2014 [34]

North et al, 2011 [35]

Perez et al, 2015 [36]

Mixed-methods survey and interview study

Experimental $2 \times 2$ design: two diff symptom vignettes (mononucleosis or scarlet fever), either Google or WebMD

Cross-sectional online survey

Analysis of inquiries posted to a health website

Experimental within-subjects design

health website and calls to a tel triage system

Experimental study with Think Aloud
Aim

Explore information seeking of patients before and after consultations, its situational influences, and its impact on patient-provider relationships

Explore the nature and content of questions and answers on a health website, and to examine the situations of patients asking questions

Analyze the search activity of users researching health information online and identify goals and patterns of search behavior

Compare older and younger adults in their performance and search behavior in ill and well-defined tasks

Examine differences between older and younger adults in interacting with different online search tasks and interfaces

Explore how women would evaluate symptoms associated with gynecologic cancers

Evaluate digital storytelling videos (videos of people talking about their own experiences) about help seeking for menopausal symptoms

Research the prevalence of health activities on social media and search engines; characterize health activities on the different platforms and describe how people evaluate information obtained from these

To gain a deeper understanding of online health-searching behavior to inform future developments of personalizing information searching and content delivery.

The Pew Internet \& American Life Project is an initiative of the Pew Research Center, a nonprofit "fact tank" that provides information on the issues, attitudes and trends shaping America and the world

Understand the extent and reasons for online research prior to first appointments for patients in a rheumatology clinic

Explore users' information-seeking difficulties by conceptualizing information seeking as a form of hypothesis testing, and to examine the role of users' competencies in online information seeking

Does the position and frequency of serious conditions in search results affect perceived severity and susceptibility, and are they related to negative emotional outcomes? Do health literacy and experience with online health seeking moderate these relationships?

Explore older adults' online health seeking to determine the cognitive and diagnostic processes involved

To determine which information resources seniors who use the Internet use and trust for health information, which sources are preferred, and which sources are used by seniors for different information needs

Describe what information people seek from a US website about genetic and rare diseases, and why

To assess the feasibility of testing a symptom appraisal tool for lung cancer symptoms in an online randomized trial

Investigate whether viewing medical websites adversely affects anxiety sensitivity

Establish what symptoms Internet users tend to look up online and whether telephone triage algorithms could be applied to these
Describe Internet search processes and identify demographic and personal characteristics associated with use of system 1 (does not include hypothesis testing and evidence gathering) and system 2 (includes hypothesis testing and evidence gathering) processing 


\begin{tabular}{lll}
\hline Author, date & Study design & Aim \\
\hline Powell et al, 2011 [37] & $\begin{array}{l}\text { Cross-sectional survey with embedded } \\
\text { qualitative semistructured interviews }\end{array}$ & $\begin{array}{l}\text { Identify the characteristics and motivations of online health information } \\
\text { seekers accessing the NHS Direct website }\end{array}$ \\
Powley et al, 2016 [38] & $\begin{array}{l}\text { Cross-sectional survey and observational } \\
\text { study }\end{array}$ & $\begin{array}{l}\text { Evaluate whether patients with inflammatory arthritis and inflammatory } \\
\text { arthralgia use the Internet for symptom appraisal and to assess the advice } \\
\text { given and diagnoses suggested by the NHS and WebMD symptom } \\
\text { checkers }\end{array}$
\end{tabular}

Rice, 2006 [39]

Teriaky et al, 2015 [40]

Cross-sectional survey

Thomson et al, 2012 [41]

White \& Horvitz, 2009 [5]

White \& Horvitz, 2009 [42] Cross-sectional survey study

White \& Horvitz, 2010 [43] Longitudinal log study using logs from Windows Live toolbar

White \& Horvitz, 2010 [44] Longitudinal log-based study

White \& Horvitz, 2012 [45] Longitudinal log-based study

White \& Horvitz, 2013 [46] Longitudinal log-based study

Ybarra \& Suman, 2006 [47] analysis of existing dataset
Cross-sectional survey study; secondary

Understand what influences online health seeking, what the reported benefits of online health seeking are, and to identify similarities among online activities

Understand how outpatients awaiting initial gastroenterology consultation seek medical information on the Internet and how wait times affect Internet usage

Explore characteristics of colorectal cancer patients who used the Web to appraise symptoms prior to diagnosis

(1) Describe escalations that occur when users search for common symptoms and how this escalates to queries about serious conditions, and (2) examine how this persists over several sessions

Explore how lay individuals use the Web to find explanations for symptoms, what activities they pursue, and what their experiences are

Predict escalations in searches based on characteristics of websites visited

Establish predictors of when searches for common symptoms lead to health care utilization

Explore how users search for medical concerns and particularly how these concerns impact on future behavior (eg how this influences focus and attention of future searches)

(1) Whether snippets in search results are biased toward serious conditions when symptoms are entered into search engines and 2) how these snippets influence user behavior

Examine which factors predict whether a Web user is likely to contact a health professional 
Table 2. Characteristics of the study populations of studies included in the review $(\mathrm{N}=32)$.

\begin{tabular}{|c|c|c|c|}
\hline Author & Study population & Setting & Sample size \\
\hline Attfield et al [6] & $\begin{array}{l}2 \text { groups of } 8 \text { NHS patients: } 1 \text { group from a Patient Advice and } \\
\text { Liaison Service (PALS) patient panel ( } 43-81 \text { years, mean 64) } \\
\text { and one group of MSc students for HCI ( } 25-42 \text { years, mean } 31)\end{array}$ & UK & 16 \\
\hline Briet et al [19] & $\begin{array}{l}\text { Users asking hand surgery-related questions from a free online } \\
\text { health consultation website }\end{array}$ & $\begin{array}{l}\text { USA (American website; no re- } \\
\text { striction regarding location of } \\
\text { website users) }\end{array}$ & 131 questions \\
\hline Cartright et al [20] & $\begin{array}{l}\text { A set of filtered logs from a toolbar deployed by the Windows } \\
\text { Live search engine, containing at least } 1 \text { symptom }\end{array}$ & $\begin{array}{l}\text { USA (English-language logs, but } \\
\text { no restriction regarding location } \\
\text { of users) }\end{array}$ & $\begin{array}{l}2,329,231 \text { actions } \\
\text { (=queries issued to a } \\
\text { search engine) }\end{array}$ \\
\hline Chin $[21]$ & Younger and older adults from a university community & USA & $\begin{array}{l}69 ; 41 \text { younger adults } \\
(18-35), 28 \text { older adults } \\
(60-83)\end{array}$ \\
\hline Chin \& Fu [22] & $\begin{array}{l}\text { Younger and older adults from community of a medium-sized } \\
\text { city }\end{array}$ & USA & $\begin{array}{l}46,23 \text { younger }(18-28) \\
\text { and } 23 \text { older }(60-77) \\
\text { adults }\end{array}$ \\
\hline Cooper et al [23] & Women aged $40-60$ years & USA & 132 \\
\hline Cumming et al [24] & Visitors of a UK-based menopause website & $\begin{array}{l}\text { UK (UK website; no restriction } \\
\text { regarding location of website } \\
\text { users) }\end{array}$ & 539 \\
\hline $\begin{array}{l}\text { De Choudhury et al } \\
{[25]}\end{array}$ & $\begin{array}{l}\text { Survey: US adults } 18-70 \text { years (census representative sampling); } \\
\text { Twitter: } 15 \text {-month sample of Twitter's Firehose stream, English- } \\
\text { language Tweets relating to health; log: data from a major Web } \\
\text { search engine }\end{array}$ & $\begin{array}{l}\text { USA (survey with US residents, } \\
\text { only English-language log data } \\
\text { but not restricted to a certain } \\
\text { country) }\end{array}$ & $\begin{array}{l}210 \text { survey respondents; } \\
125,166,549 \text { tweets; } \\
174,605,024 \text { searches }\end{array}$ \\
\hline Fiksdal et al [26] & $\begin{array}{l}\text { Adult, English-speaking members of the Olmsted County, MN } \\
\text { community (where Mayo Clinic is located) and Mayo Clinic } \\
\text { patients, employees, and family visitors }\end{array}$ & USA & 19 \\
\hline Fox \& Duggan [1] & Adults living in the United States & USA & 3014 \\
\hline Hay et al [27] & English-speaking US adults ( $\geq 17$ years) & USA & 120 \\
\hline Keselman et al [28] & Lay individuals (convenience sample) & USA & 20 \\
\hline Lauckner \& Hsieh [29] & $\begin{array}{l}\text { Students from an undergraduate communication course at a } \\
\text { large Midwestern university }\end{array}$ & USA & 274 \\
\hline Luger [30] & $\begin{array}{l}\text { Older US adults, } \geq 50 \text { years, community resident, without cog- } \\
\text { nitive impairment, who owned a computer }\end{array}$ & USA & 79 \\
\hline Medlock et al [31] & Members of a local senior (Christian) organization & Netherlands & 118 \\
\hline Morgan et al [32] & $\begin{array}{l}\text { Random sample of English-language inquiries posted by lay } \\
\text { people to the question and answer section of the GARD website } \\
\text { and inquiries sent via email }\end{array}$ & $\begin{array}{l}\text { USA (American website but no } \\
\text { restrictions on locale of users) }\end{array}$ & $\begin{array}{l}278 \text { inquiries, } 68 \text { from } \\
2006 \text { and } 210 \text { from } \\
2011\end{array}$ \\
\hline Mueller et al [33] & $\begin{array}{l}\text { Adults living in UK with undiagnosed symptoms potentially } \\
\text { related to lung cancer }\end{array}$ & UK & 97 \\
\hline Norr et al [34] & $\begin{array}{l}\text { Undergraduate students from a large university in the Southern } \\
\text { United States. }\end{array}$ & USA & 56 \\
\hline North et al [35] & $\begin{array}{l}\text { All symptom assessment callers to Ask Mayo Clinic (telephone } \\
\text { triage) and all clicks to specific symptoms on the symptom- } \\
\text { checker page of MayoClinic.com }\end{array}$ & USA & $\begin{array}{l}70,370 \text { calls; } 2,059,299 \\
\text { clicks }\end{array}$ \\
\hline Perez et al [36] & $\begin{array}{l}\text { Young adults aged } 21-35 \text { with experience of online health infor- } \\
\text { mation and reported barriers to accessing health services }\end{array}$ & USA & 78 \\
\hline Powell et al [37] & Users of the NHS Direct website & UK & $\begin{array}{l}792 \text { for survey, } 26 \text { for } \\
\text { interviews }\end{array}$ \\
\hline Powley et al [38] & $\begin{array}{l}\text { Newly presenting patients with either clinically apparent syn- } \\
\text { ovitis or a new onset of symptoms consistent with inflammatory } \\
\text { arthritis but without clinically apparent synovial swelling attend- } \\
\text { ing a secondary care based rheumatology clinic }\end{array}$ & UK & 34 \\
\hline
\end{tabular}




\begin{tabular}{|c|c|c|c|}
\hline Author & Study population & Setting & Sample size \\
\hline Rice [39] & $\begin{array}{l}\text { US adults: respondents from studies conducted within the Pew } \\
\text { Internet and American Life project }\end{array}$ & USA & $\begin{array}{l}13,978 \text { respondents in } \\
2000 \text { who reported } \\
\text { health seeking online, } \\
500 \text { of these were tele- } \\
\text { phone interviewed in } \\
2001\end{array}$ \\
\hline Teriaky et al [40] & $\begin{array}{l}\text { Patients awaiting appointments at a general gastroenterology } \\
\text { clinic in London, ON, Canada }\end{array}$ & Canada & 87 \\
\hline Thomson et al [41] & Newly diagnosed colorectal cancer patients ( $<6$ months) & USA & 242 \\
\hline White \& Horvitz [5] & $\begin{array}{l}\text { Log data related to symptom queries (no mention of restriction } \\
\text { by locale) from all major Web search engines (eg, Google, } \\
\text { Yahoo!, or Live Survey): randomly selected employees of the } \\
\text { Microsoft Corporation who had performed at least } 1 \text { health-re- } \\
\text { lated online search; survey: Microsoft employees }\end{array}$ & $\begin{array}{l}\text { USA (survey with US residents, } \\
\text { no restriction mentioned regard- } \\
\text { ing locale for logs) }\end{array}$ & $\begin{array}{l}\text { Logs: } 8732 \text { users with } \\
\text { symptom-related } \\
\text { queries; survey: } 515 \\
\text { participants }\end{array}$ \\
\hline White \& Horvitz [42] & $\begin{array}{l}5000 \text { Microsoft employees were invited via email, from these } \\
\text { volunteers were chosen who indicated in a prescreening that } \\
\text { they searched the Web for medical information }\end{array}$ & USA & 515 survey respondents \\
\hline White \& Horvitz [43] & $\begin{array}{l}\text { Logs from windows live browser toolbar, English-speaking } \\
\text { USA relating to } 6 \text { basic symptoms }\end{array}$ & $\begin{array}{l}\text { USA (log data issued from US } \\
\text { locale) }\end{array}$ & $\begin{array}{l}\text { "Many thousands of } \\
\text { logs were mined" }\end{array}$ \\
\hline White \& Horvitz [44] & $\begin{array}{l}\text { Logs from consenting Windows live toolbar users over a 6- } \\
\text { month period relating to } 3 \text { symptoms: chest pain, muscle } \\
\text { twitches, abdominal pain }\end{array}$ & $\begin{array}{l}\text { USA (log data issued from US } \\
\text { locale) }\end{array}$ & $\begin{array}{l}700 \text { queries with symp- } \\
\text { tom to HUI transition; } \\
700 \text { queries with symp- } \\
\text { toms to no HUI transi- } \\
\text { tion }\end{array}$ \\
\hline White \& Horvitz [45] & $\begin{array}{l}\text { Logs from consenting Windows live toolbar users over a 3- } \\
\text { month period }\end{array}$ & $\begin{array}{l}\text { USA (log data issued from US } \\
\text { locale) }\end{array}$ & 169,513 queries \\
\hline White \& Horvitz [46] & $\begin{array}{l}\text { Log data related to symptoms queries generated in English- } \\
\text { speaking US locale }\end{array}$ & $\begin{array}{l}\text { USA (log data issued from US } \\
\text { locale) }\end{array}$ & $\begin{array}{l}2070 \text { symptom queries } \\
\text { from } 714 \text { users }\end{array}$ \\
\hline Ybarra \& Suman [47] & $\begin{array}{l}\text { Americans living throughout the } 50 \text { states and the District of } \\
\text { Columbia }\end{array}$ & USA & $\begin{array}{l}\text { Year } 1=2104 \text {; year } 4 \text { : } \\
2010,570 \text { of these were } \\
\text { year } 1 \text { participants }\end{array}$ \\
\hline
\end{tabular}


Table 3. Nature of measures and procedures of studies included in the review $(\mathrm{N}=32)$.

\begin{tabular}{ll}
\hline Author & Nature of measures and procedure \\
\hline Attfield et al [6] & $\begin{array}{l}\text { Semistructured interviews, eliciting accounts of health information-seeking episodes and how they relate to ongoing health } \\
\text { care }\end{array}$
\end{tabular}

Briet et al [19] Questions and answers to a health website were categorized and analyzed descriptively

Cartright et al [20] Logs were mined and categorized as either evidence-directed, hypothesis-directed with diagnostic intent, or hypothesis-directed with informational intent, according to defined algorithms

Chin [21] Participants were randomized to complete either an ill-defined task (find possible causes for a list of symptoms) or well-defined task (find a specific medical term), using a health website; cognitive measures (working memory capacity, processing speed), health literacy measures, medical knowledge measure, search performance for both tasks were measured

Chin \& Fu [22] Participants were given a symptom vignette and asked to find possible causes. Participants were randomized to complete either a parts task (described symptoms based on body parts) or a systems task (described symptoms by functional systems). Tasks were completed either in the parts interface (categorized symptoms based on body parts) or systems interface (categorized symptoms based on functional body systems). Measures included Patients' Medical Background Knowledge, Mental Interface Match Index, Broadness (no. of links), link decision time: time spent reading.

Cooper et al [23] Discussion in focus groups: which symptoms from a list would be of most concern, why, and what could cause them, what would be their hypothetical response to them, what were actual responses in the past?

Cumming et al [24] Participants viewed a storytelling video online and then completed a questionnaire evaluating the effect of the video on feeling informed, planned future help seeking, etc

De Choudhury et al In the survey, participants were asked questions about their experiences using Twitter and search engines to share and seek health information; on the log analysis, tweets and logs were categorized as relating to 4 categories: (1) symptoms of major diseases, (2) benign explanations (nonlife-threatening illnesses), (3) serious illnesses, and (4) disabilities; logs were then analyzed descriptively

Fiksdal et al [26] Moderators used a semistructured moderator guide to facilitate discussion in focus groups about: (1) participants' perception and understanding of health care information, (2) the process of information collection on the Internet, (3) understanding and usage of information, and (4) implications of health care information for health and well-being

Fox \& Duggan [1] People were contacted via telephone for telephone interviews about online health information seeking

Hay et al [27] Before their appointment, patients were interviewed about online health information (OHI) seeking, and completed the WongBaker-Faces Pain Scale; the consultation was audio-recorded to determine whether OHI was mentioned and then patients completed a satisfaction scale regarding the consultation

Keselman et al [28] Participants read a hypothetical scenario describing a relative who experienced symptoms typical of stable angina and then discussed possible causes of symptoms from the symptom vignettes in semistructured interviews; then Think Aloud while they researched symptoms on MedlinePlus

Lauckner \& Hsieh The study took place online; participants were presented with a symptom vignette and then with a search engine result page

Luger [30] manipulated to show serious conditions either at the top or bottom, and low or high frequency of serious conditions; participants then completed several scales: perceptions of severity and susceptibility using the Risk Behavior Diagnosis scale, history of viewing online health information, their health status, how often they experienced each of the 4 symptoms, and their demographic information, health literacy using the Newest Vital Sign (NVS)

Participants were presented with 1 of 2 symptom vignettes and asked to diagnose them using Think Aloud, either on Google or WebMD. Measures taken included Think Aloud, self-reported age, gender, ethnicity, education, and income, recent health history, number of hours per week that they used a home computer as well as the number of years that they had owned a home computer, whether or not they had previous experience with the Internet tool to which they were assigned (Google or WebMD's Symptom Checker).

Medlock et al [31] Participants completed an online questionnaire, which included questions about health information resources used; the Autonomy Preference Index was used to assess information needs and preferences for involvement in health decisions

Morgan et al [32] A random sample of questions posted to the GARD website were analyzed thematically; collected data included inquiry origin (domestic), type of contact (email and Web-based form), gender, date received at the information center, the specific condition for which they were inquiring, primary language (English), and their reason for inquiry

Mueller et al [33] Participants first completed a survey about their symptoms and risk factors. They were then randomized to receive the intervention (personalized, theory-based health webpages), or control conditions. Subsequently, participants completed a questionnaire which assessed demographic details, participants' self-reported intention to seek help (scale 1-7), behavioral attitudes and beliefs about help seeking.

Norr et al [34] Participants first completed the Anxiety Sensitivity Index (ASI), Intolerance of Uncertainty Scale (IUS), and a health anxiety scale (SHAI). Participants were randomized to view either symptom-related websites or general health and wellness control websites. Afterwards, they completed the ASI and SHAI.

North et al [35] For the MayoClinic website, click data was collected using Google Analytics; for the telephone triage, all completed calls were counted and put into symptom categories based on the algorithm/guideline used during the call. 


\begin{tabular}{ll}
\hline Author & Nature of measures and procedure \\
\hline Perez et al [36] & $\begin{array}{l}\text { Participants were randomized to one of two symptom scenarios and instructed to search the Internet while using Think Aloud; } \\
\text { participants' Internet searches and think-out-loud vocalizations were digitally recorded using screen capture video-recording } \\
\text { software }\end{array}$
\end{tabular}

Powell et al [37] Users of the NHS Direct website completed an online questionnaire survey. A subsample of survey respondents participated in in-depth, semistructured, qualitative interviews by telephone or instant messaging/email.

Powley et al [38] Patients completed a brief survey on Internet use for symptom appraisal prior to attending clinic; patients were then asked to complete the NHS and WebMD symptom checkers based on their symptoms and their answers and the outcomes were recorded; demographic and disease-related data were obtained from clinic records.

Rice [39] Respondents were contacted via telephone for telephone interviews asking about online health seeking.

Teriaky et al [40] Patients awaiting gastroenterology consultation were asked to complete a questionnaire consisting of 16 multiple-choice questions to understand patient use of Web resources for medical information. Abstracted information included patient demographics, level of education, reason for referral, preceding investigations, patient resources utilized, websites browsed, information obtained, reasons for seeking information on the Internet, patient self-diagnosis, and lifestyle changes instituted.

Thomson et al [41] Semistructured interviews focused on patient sociodemographic and psychological factors, symptom recognition and appraisal, and communication with HCPs, friends, and family.

White \& Horvitz [5] Analysis of logs: Formulated a list of symptoms and associated benign and serious conditions. Recorded all queries to search engines and clicks on result pages, and identified those that included symptoms as search terms. Escalations: Observed increases in medical severity of search terms within a search session. Nonescalations: Search progresses to benign explanation of the symptom; survey: Microsoft employees were sent a survey with open and closed-ended questions regarding participants' medical history and online search behavior

White \& Horvitz [42] Microsoft employees were sent a survey to elicit perceptions of online medical information, experiences in searching for this information, and the influence of the Web on health care concerns and interests. The survey contained "around 70" open and closed questions

White \& Horvitz [43] Cases were identified where queries for symptoms were followed by a query about a related serious condition. Cases where it led to a benign query or no change were termed nonescalations. Using logistic regression, a model was developed to predict escalation using website features of the previously visited page; website features: structural features, title and URL features, firs-person testimonials, page reliability/credibility, commercial intent

White \& Horvitz [44] Log analysis: logs containing symptoms as search terms were filtered, and it was determined whether subsequent searches showed health care utilization intent (HUI). Logistic regression was used to predict HUI based on search characteristics; log entries include a user identifier, a timestamp for each page view, and the URL of the page visited; HUI: queries that indicate searching for contact information for medical facilities

White \& Horvitz [45] Queries were labeled to identify medical and symptoms related queries, and escalations. Subsequently occurring searches were examined. Log entries included a unique user identifier, a timestamp for each page view. Search sessions on Google, Yahoo!, and Bing. Escalation queries were categorized as within-session and between session

White \& Horvitz [46] Log data relating to symptom queries were filtered. Subsequent behavior on the search engine result page was examined, including hovering, cursor movements, clicks, scrolling, as well as bounding boxes of areas of interest (AOIs)

Ybarra \& Suman [47] Respondents were contacted via telephone and completed a telephone survey about online health information seeking and help-seeking behavior (seeking help from a health professional or others)

As Table 4 shows, some studies explored Web use regarding current symptoms $(\mathrm{n}=5)$ or symptoms that had been experienced previously $(\mathrm{n}=7)$, or both $(\mathrm{n}=1)$, whereas other studies examined Web use for symptom appraisal by providing participants with a symptom vignette and instructing them to imagine they have these symptoms $(n=8)$. In several studies $(n=11)$, the exact situation of participants was unclear because anonymous data were collected online. Table 4 also highlights the variety and nonspecificity of symptoms examined; most studies $(n=15)$ examined general symptoms and although 10 studies examined specific conditions, only two studies examined similar conditions [27,38]. Finally, most studies $(n=20)$ did not follow up whether participants had received a diagnosis. 
Table 4. Symptoms and diagnoses examined in included studies.

\begin{tabular}{|c|c|c|}
\hline Author, date & $\begin{array}{l}\text { Were participants symptomatic, } \\
\text { asymptomatic, or previously symp- } \\
\text { tomatic }^{a_{2}}\end{array}$ & Type of symptoms examined \\
\hline Attfield et al [6] & Previously symptomatic & General (any symptoms) \\
\hline Briet et al [19] & $\begin{array}{l}\text { Unclear, participants were users asking } \\
\text { questions about symptoms }{ }^{b}\end{array}$ & Hand illness-related symptoms \\
\hline Cartright et al [20] & $\begin{array}{l}\text { Unclear, participants were users issuing } \\
\text { symptom-related queries to a search } \\
\text { engine }^{b}\end{array}$ & General $^{\mathrm{c}}$ \\
\hline Chin [21] & $\begin{array}{l}\text { Asymptomatic, participants were pre- } \\
\text { sented with a symptom vignette }\end{array}$ & $\begin{array}{l}\text { Symptom vignettes included: pain and } \\
\text { stiffness in the body; burning, itching, and } \\
\text { sometimes tingling sensation on their } \\
\text { body; feeling feverish and chilly after an } \\
\text { overseas trip; fatigue, sudden weight gain } \\
\text { and difficulty dealing with cold; however, } \\
\text { results were not analyzed separately for } \\
\text { different symptoms }\end{array}$ \\
\hline
\end{tabular}

Chin \& Fu [22] Asymptomatic; participants were presented with a symptom vignette

Cooper et al [23] Asymptomatic; participants were presented with a list of symptoms

Cumming et al [24] Most symptomatic (448/492), but some asymptomatic (44/492)

De Choudhury et al Unclear, participants were users issuing [25]

Fiksdal et al [26]

Fox \& Duggan [1] Previously symptomatic symptom-related Tweets and queries to a search engine ${ }^{b}$

Previously symptomatic

Hay et al [27]

Keselman et al [28]

Lauckner \& Hsieh [29]

Luger [30]

Medlock et al [31]

Morgan et al [32] Unclear, participants were users issuing

Mueller et al [33] $\quad 87$ participants were symptomatic, 10

Norr et al [34] symptom vignette symptom-related Tweets and queries to a search engine ${ }^{b}$ were asymptomatic but searching on behalf of someone else

Symptomatic; participants were newly Rheumatoid symptoms diagnosed rheumatology patient Asymptomatic; partic
symptom vignette Asymptomatic; participants received a symptom vignette

Asymptomatic; participants viewed a list of symptoms ly or rare disease
Did the study follow up whether Web use was followed by a diagnosis?

\section{Not assessed}

Not assessed

Not assessed

Not applicable ${ }^{\mathrm{d}}$

General (participants received 6 different Not applicable ${ }^{\mathrm{d}}$ vignettes with different symptoms, not assessed separately)

Symptoms related to gynecologic cancers

Menopausal symptoms

General, logs were filtered for references to symptoms using a comprehensive list of symptoms from the Merck medical dictionary

General (any symptoms)

General (any symptoms)

Not assessed

Participants were asked whether their diagnosis was confirmed by a health professional; $45 \%$ said it was confirmed, $35 \%$ did not present, $19 \%$ said it was not confirmed/inconclusive

Yes, patients' diagnoses were gathered after the appointment or at follow-up appointment

Not applicable ${ }^{\mathrm{d}}$

Not applicable ${ }^{\mathrm{d}}$

Symptom vignettes involved one of four symptoms: headaches, chest pain, muscle twitches, or abdominal pain, but the different symptoms were not analyzed separate-

Symptom vignettes involved either mononucleosis or scarlet fever

General (any symptoms)

Not applicable ${ }^{\mathrm{d}}$

Not assessed

Symptoms related to any type of genetic Not assessed

Symptoms related to lung cancer

Not assessed

General ("websites focused on symptoms Not applicable $^{\mathrm{d}}$ of medical conditions") 


\begin{tabular}{|c|c|c|c|}
\hline Author, date & $\begin{array}{l}\text { Were participants symptomatic, } \\
\text { asymptomatic, or previously symp- } \\
\text { tomatic }^{a_{\text {a }}}\end{array}$ & Type of symptoms examined & $\begin{array}{l}\text { Did the study follow up whether Web use } \\
\text { was followed by a diagnosis? }\end{array}$ \\
\hline North et al [35] & $\begin{array}{l}\text { Unclear, participants were users } \\
\text { searching the MayoClinic website or } \\
\text { using a telephone triage }^{\mathrm{b}}\end{array}$ & General (any symptoms) & Not assessed \\
\hline Perez et al [36] & $\begin{array}{l}\text { Asymptomatic; participants received a } \\
\text { symptom vignette }\end{array}$ & $\begin{array}{l}\text { One of two clinical symptom scenarios: } \\
\text { (1) fever, mild headache, dry cough, and } \\
\text { myalgia, suggestive of influenza, and ( } 2 \text { ) } \\
\text { fever, severe headache, and stiff neck, } \\
\text { suggestive of meningitis }\end{array}$ & Not applicable ${ }^{\mathrm{d}}$ \\
\hline Powell et al [37] & $\begin{array}{l}\text { Unclear, participants were users of the } \\
\text { NHS website }\end{array}$ & General (any symptoms) & Not assessed \\
\hline Powley et al [38] & $\begin{array}{l}\text { Symptomatic; participants were pa- } \\
\text { tients attending a secondary care based } \\
\text { rheumatology clinic }\end{array}$ & $\begin{array}{l}\text { Either clinically apparent synovitis or a } \\
\text { new onset of symptoms consistent with } \\
\text { inflammatory arthritis but without clinical- } \\
\text { ly apparent synovial swelling }\end{array}$ & $\begin{array}{l}\text { Yes, rheumatological diagnosis was } \\
\text { recorded after consultation }\end{array}$ \\
\hline Rice [39] & Previously symptomatic & General (any symptoms) & Not assessed \\
\hline Teriaky et al [40] & $\begin{array}{l}\text { Symptomatic; participants were pa- } \\
\text { tients awaiting gastroenterology ap- } \\
\text { pointments }\end{array}$ & Symptoms related to gastroenterology & Not assessed \\
\hline Thomson et al [41] & $\begin{array}{l}\text { Symptomatic; participants were colorec- } \\
\text { tal cancer patients }\end{array}$ & Symptoms related to colorectal cancer & $\begin{array}{l}\text { Yes; all participants were diagnosed with } \\
\text { colorectal cancer }\end{array}$ \\
\hline White \& Horvitz [5] & $\begin{array}{l}\text { Logs: Unclear, participants were users } \\
\text { issuing symptom-related queries to a } \\
\text { search engine }{ }^{\text {b }} \text {; survey: previously } \\
\text { symptomatic }\end{array}$ & $\begin{array}{l}\text { Logs related to } 3 \text { common symptoms } \\
\text { (headache, muscle twitches, and chest } \\
\text { pain) }\end{array}$ & Not assessed \\
\hline $\begin{array}{l}\text { White \& Horvitz } \\
\text { [42] }\end{array}$ & Previously symptomatic & General (any symptoms) & Not assessed \\
\hline $\begin{array}{l}\text { White \& Horvitz } \\
\text { [43] }\end{array}$ & $\begin{array}{l}\text { Unclear, participants were users issuing } \\
\text { symptom-related queries to a search } \\
\text { engine }^{b}\end{array}$ & $\begin{array}{l}\text { Queries related to any of } 6 \text { common } \\
\text { symptoms: headache, chest pain, muscle } \\
\text { twitches, abdominal pain, nausea, and } \\
\text { dizziness }\end{array}$ & Not assessed \\
\hline $\begin{array}{l}\text { White \& Horvitz } \\
\text { [44] }\end{array}$ & $\begin{array}{l}\text { Unclear, participants were users issuing } \\
\text { symptom-related queries to a search } \\
\text { engine }^{b}\end{array}$ & $\begin{array}{l}\text { Queries related to one of } 3 \text { symptoms: } \\
\text { chest pain, muscle twitches, and abdomi- } \\
\text { nal pain }\end{array}$ & Not assessed \\
\hline $\begin{array}{l}\text { White \& Horvitz } \\
\text { [45] }\end{array}$ & $\begin{array}{l}\text { Unclear, participants were users issuing } \\
\text { symptom-related queries to a search } \\
\text { engine }\end{array}$ & General $^{\mathrm{c}}$ & Not assessed \\
\hline $\begin{array}{l}\text { White \& Horvitz } \\
\text { [46] }\end{array}$ & $\begin{array}{l}\text { Unclear, participants were users issuing } \\
\text { symptom-related queries to a search } \\
\text { engine }^{b}\end{array}$ & General $^{\mathrm{c}}$ & Not assessed \\
\hline $\begin{array}{l}\text { Ybarra \& Suman } \\
\text { [47] }\end{array}$ & Previously symptomatic & General (any symptoms) & Not assessed \\
\hline
\end{tabular}

\footnotetext{
${ }^{\text {a }}$ Symptomatic: participants experienced the symptoms at the time of the study; asymptomatic: participants did not have symptoms and were surveyed regarding fictional symptoms; previously symptomatic: participants were surveyed about symptoms they experienced previously.

${ }^{\mathrm{b}}$ Participants were users asking questions about symptoms (could be own symptoms or asking on behalf of someone else).

${ }^{\mathrm{c}}$ Any queries related to a comprehensive list of symptoms from the Merck medical dictionary.

${ }^{\mathrm{d}}$ Patients were not symptomatic.
}

\section{Quality Assessment and Risk of Bias}

Quality assessment of the studies is shown in Multimedia Appendix 3. Subsequently, we use this information to critically appraise evidence from the studies and assess risk of bias.

\section{What Proportion of Different Populations Use the Web to Appraise Symptoms?}

Four studies, all surveys, reported the proportion of the study sample that engaged in Web use for symptom appraisal (Table $5)$. 
Table 5. Percentage of people engaging in Web use for symptom appraisal reported by included studies $(n=4)$.

\begin{tabular}{llll}
\hline Reference & Study population & Sample size & $\begin{array}{l}\text { Reported Web use for symptom appraisal, \% (95\% } \\
\text { CI) }\end{array}$ \\
\hline Fox \& Duggan [1] & Adults living in the US & 3014 & $35 \%(33 \%-37 \%)$ \\
White \& Horvitz [42] & US Microsoft employees & 515 & $75 \%(71 \%-79 \%)$ \\
Medlock et al [31] & $\begin{array}{l}\text { Members of a senior church organization, } \\
\text { Netherlands }\end{array}$ & 118 & $23 \%(15 \%-31 \%)$ \\
Thomson et al [41] & Colorectal cancer patients, US & 242 & $25 \%(20 \%-31 \%)$ \\
\hline
\end{tabular}

In Fox and Duggan's [1] population-based survey with adults living in the United States, $35 \%$ reported going online to attempt self-diagnosis. Participants were sampled to mirror the population in terms of demographics, but disproportionately stratified to increase the incidence of nonwhite respondents. This survey was conducted in the United States and is therefore likely to reflect proportions in Western, high-income countries with high Internet penetration.

White and Horvitz's [42] survey conducted among Microsoft employees found that "three-quarters of subjects" (the authors do not provide absolute numbers; assuming the proportion is $75 \%$ of $\mathrm{N}=515,95 \%$ CI $71 \%-79 \%$ ) reported searching for information on symptoms. "Two-thirds" reported researching professionally undiagnosed conditions, at least once a month [42]. It should be noted that this sample was biased toward younger, male respondents with high educational level and socioeconomic status working within an industry that is very Web-oriented.

Medlock et al [31] examined online health information seeking in older people by surveying members of a senior Christian organization. They found that $23 \%$ of participants reported using the Web in the past 12 months to determine the cause of symptoms. This shows that, although Web use for symptom appraisal may be less common among older people than in the general population (compared to 33\%-37\% found by Fox and Duggan [1]), older people do engage in it.

While the previous surveys focused on diagnostic searches for any conditions/symptoms, Thomson et al [41] conducted a survey with colorectal cancer patients and found that $25 \%$ of the sample reported prediagnosis Web use for symptom appraisal.

To conclude, Fox and Duggan's [1] study with its large, population-based sample size is most likely to give an accurate proportion for the general population (in a Western, higher income country), although the other included studies give an indication of how this proportion can vary depending on the population being surveyed (ie, depending on sociodemographic variables and disease-related factors). It should also be noted that the confidence intervals are wide in a number of these studies reflecting considerable uncertainty about the true proportion.

Which Symptoms Are Likely to Be Researched Online?

Six studies examined characteristics of symptoms that were searched for online $[25-27,35,39,41]$. Three of these were survey studies [27,39,41], one was an interview study [26], and two involved analyses of data on usage of online resources such as social media, search engines, and health websites $[25,35]$.

North et al [35] compared users of the Mayo Clinic website with people who used a telephone triage system to appraise their symptoms and found that telephone triage users were more likely to have acute and conspicuous symptoms requiring immediate relief, whereas website users were more likely to research chronic conditions. Hay et al [27] surveyed rheumatology patients and found that some individuals in their study sought help online because they had a history of undiagnosed symptoms. Findings from both of these studies suggest symptoms are researched online when they have been present for a prolonged time.

In their study on colorectal cancer patients, Thomson et al [41] found that neither symptom severity nor stage at diagnosis was related to Web use for symptom appraisal, but Web users were more likely to experience symptoms typically perceived as embarrassing, such as change in bowel habits. Similarly, Choudhury et al [25], who analyzed log data obtained from Twitter and a search engine, found that potentially embarrassing, stigmatized, or sensitive symptoms such as "vaginal bleeding" or "pelvic pain" were more likely to be searched for than tweeted. Furthermore, Rice's [39] population-based telephone survey conducted in the United States concluded that more frequent online health seekers were more likely to look for sensitive health topics that are difficult to talk about than less frequent online health seekers.

Finally, in Fiksdal et al's [26] focus group study with 19 US adults, participants reported turning to the Web when symptoms were perceived as trivial/nonserious and they wanted to avoid "bothering" health professionals.

In conclusion, it appears Web use for symptom appraisal occurs when symptoms are persistent, have a history of being undiagnosed by health professionals, are potentially embarrassing or stigmatized, and/or when they are perceived as superficial/nonserious.

\section{How Is Web Use for Symptom Appraisal Conducted (Search Strategies)?}

\section{Theme 1: Symptom-Based, Condition-Based, and Treatment-Based Searches}

Three distinct approaches to searching were identified: (1) symptom-based searches, which used symptoms as search terms; (2) condition-based searches, which involved searches for particular conditions, and (3) treatment-based searches, which 
involved researching treatments for symptoms without prior research on possible causes.

Log data from search engines suggest the majority $(65 \%)$ of exploratory health-related searches (ie, those aimed at diagnosing a condition) are symptom-based rather than condition-based [20], and remain symptom-based throughout the search because search sessions tend to start and end with purely symptom-related queries [5,20]. One should bear in mind, however, that log-based studies cannot ascertain searchers' actual intentions and motivations. The authors assume occurrences of certain search terms signal certain intentions (eg, a symptom and the term "cause" signals diagnostic intent); however, articles did not report any prior validation of these algorithms.

An experimental study that observed people $(\mathrm{N}=79)$ as they used Google or a symptom-checker tool to diagnose symptom vignettes reported that most users conduct symptom-based searches because most people began their search by entering symptoms and only $24 \%$ began by specifying a condition [30].

In an experimental study conducted by Perez et al [36], participants $(\mathrm{N}=78)$ were instructed to research the Web as if they were experiencing a given symptom, described in a vignette, while using Think Aloud. Think Aloud (also known as "cognitive interviewing") requires participants to vocalize their thoughts while performing a task [48]. The authors found that $19 \%$ of searches were treatment-based and the remainder symptom- or condition-based (the authors did not report these separately). It should be noted that the external validity of vignette-based studies is limited because individuals base their searches on the vignette descriptions rather than actual perceptions or observations, and the search behavior observed is likely to depend on the phrasing of the vignette.

Keselman et al [28] used interview and Think Aloud methods to explore how a convenience sample of 20 lay individuals interpreted a symptom vignette using the American consumer health information service MedlinePlus. They concluded that some participants conducted condition-based searches and some participants used a symptom-based approach. Additionally, they identified a group of participants who used a condition-based approach, but began their search with a broader hypothesis, such as "heart disease," and then attempted to narrow down their search. Different barriers seemed to play a role in the different search strategies: condition-based searchers were prone to confirmation bias, seeking out information that confirmed their hypothesis and terminating the search before reviewing further hypotheses. Those starting with a broad hypothesis often terminated the search without coming to a conclusion. The symptom-based searchers struggled to find the relevant results due to the lack of specificity of their search terms [28].

Overall, it seems most Web use for symptom appraisal searches are symptom-based and both log-based studies, which have high external validity, and experimental studies, which have high internal validity, confirm this finding. No validation was reported for the algorithms used for the log-based studies, however, and experimental and qualitative studies used to observe search behavior have limited generalizability to real-world contexts.

\section{Theme 2: Selection of Search Terms}

Keselman et al [28] examined the search behavior of 20 adults using Think Aloud and discovered that participants often ignored symptoms mentioned in the vignette if they perceived them as irrelevant and exempted these from their search terms. The authors termed this "selective perception bias." The participants also tended to ignore aspects of duration of the symptoms and had difficulty discerning acute from chronic symptoms. However, these findings stem from a single study with only 20 adults using fictional scenarios, thus further validation is required.

\section{Theme 3: Age Differences}

Three studies reported on age differences in search behavior [21,22,30]. Chin et al [21] $(\mathrm{N}=69)$ compared the search performance of younger and older adults while performing either a well-defined task (searching for a specific medical term on a website) or an ill-defined task (using the website to diagnose a set of symptoms). The study found that older adults performed better in the ill-defined task, whereas younger participants performed better in the well-defined task [21].

In another study $(\mathrm{N}=46)$, Chin and Fu [22] presented older and younger adults with different interfaces of the same website: one interface categorized symptoms based on the body parts they occurred in and the other interface categorized symptoms according to functional systems (eg, respiratory system). Younger adults tended to click on significantly more links within one category, suggesting they followed the interface of the website, whereas older adults clicked significantly more between-category links regardless of the interface. Chin and $\mathrm{Fu}$ [22] conclude this was due to older adults using their existing medical knowledge rather than the interface to guide their search, which is supported by their finding that older adults performed better in a medical knowledge task [22].

Luger at al [30] explored the search behavior of adults aged 50 years and older $(\mathrm{N}=79)$ in a Think Aloud study and found that participants who accurately diagnosed the condition presented in a symptom vignette were slightly younger (mean 61.72, SD 6.17 years) than those who were inaccurate (mean 65.51, SD 7.54 years), although no inferential statistics were reported.

Thus, there are some indications that older adults perform differently in Web searches for symptom appraisal than younger adults, possibly due to medical knowledge. However, the available studies used small sample sizes, thus inferences to the wider population may not be appropriate.

\section{Theme 4: Selecting Information}

Several studies examined how users select information from their search results. We identified four subthemes relating to selection of information.

\section{Number of Search Results Viewed}

Lauckner and Hsieh [29] reported that participants in their laboratory-based, experimental study with undergraduate students $(\mathrm{N}=274)$ viewed approximately four links on results pages, which was the number of results visible above the "fold" (ie, users would need to scroll down to view more results). Corroborating this finding, Keselman et al [28] discovered that 
participants in their qualitative study $(\mathrm{N}=20)$ often ignored relevant links while trying to diagnose a symptom vignette if these were located below the fold. Luger et al [30] found that older adults $(\mathrm{N}=79)$ in their experimental, laboratory-based study tended to view approximately six conditions on the WebMD symptom-checker tool after entering a set of symptoms, although the authors do not clarify whether this was the number visible above the fold.

Thus, the top results returned by search engines will have maximum impact on symptom appraisal, whereas those located below the fold may have little to no effect. Because these findings all relate to laboratory-based studies, however, further investigation in naturalistic settings would be beneficial.

\section{Process of Elimination}

In their study using Think Aloud with 79 adults aged 50 years and older, Luger et al [30] found that $91 \%$ of participants used a "process of elimination," whereby the symptoms described in the vignette were compared against those listed for a given condition and the condition was discarded as a hypothesis if it included symptoms not mentioned in the vignette. This finding suggests that a common search strategy is to narrow down the hypotheses by discarding those with symptoms not matching one's own. However, the majority of the sample was highly educated (all had some university education), therefore generalizability to the wider population is unclear.

\section{Source Credibility}

In Luger et al's [30] study with adults aged 50 years and older $(\mathrm{N}=79)$, source credibility was mentioned by only $25 \%$ of the sample. They also found that one-third viewed user-generated content such as discussion boards, which are not quality controlled. White and Horvitz [46] found in their log-based study that consumer sites such as MayoClinic.com or WebMD (both well-known American corporations and health websites) are positively related to click-through rates following searches that contain symptoms as search terms, suggesting widely known, established health websites are likely to be accessed during Web use for symptom appraisal. White and Horvitz [5] also suggest searches that "escalate" (ie, progress from searching for symptoms to serious conditions) contain more visits to "trusted sources" (eg, governmental websites, websites of health organizations). It is important to note that although the authors claim to research "diagnostic searches," this was identified through the presence of symptoms in search terms and may therefore also include nondiagnostic searches.

\section{Pages Mentioning Serious Illnesses}

White and Horvitz [46] filtered logs from a search engine and examined how users issuing symptom queries subsequently interacted with search results pages. They found that users engage more with captions on search results pages that mention serious illnesses, hovering more frequently and longer over these captions and clicking these more often than captions mentioning benign causes. Terminology related to serious illnesses such as "malignant," "severe," and "tumor" significantly increased click probability, whereas terms such as "benign" decreased click probability. Additionally, users were more likely to engage with sites indicating they can help identify causes of symptoms (eg, by mentioning the words "learn" and "causes").

Although we do not know searchers' intentions or how they used the information found, these findings suggest those researching symptoms online are more likely to engage with websites relating to serious causes.

To summarize, Web use for symptom appraisal typically involves inputting information into a search tool and subsequently narrowing down results returned by the search tool. When inputting information, most users appear to choose search terms based on symptoms rather than hypothesized conditions, but users do not appear to utilize all information available (eg, some symptoms may be omitted, as well as the frequency/duration of symptoms). Furthermore, there is some limited evidence that older adults perform differently in Web searches for symptom appraisal than younger adults, and that this may be due to medical knowledge. Once a selection of results is provided by the search tool, users tend to narrow results down by taking into account the results' position on the results page, the degree of seriousness of the condition, the credibility of the source, and the extent of overlap between the listed and the experienced symptoms.

\section{Behavioral Consequences of Web Use for Symptom Appraisal}

\section{Theme 1: Increased Help Seeking}

In Fox and Duggan's [1] population-based survey $(\mathrm{N}=3014)$, $46 \%$ (95\% CI 44.22\%-47.78\%) of online self-diagnosers claimed that information found online led them to think they needed the attention of a health professional. Thomson et al [41] found in their survey with colorectal cancer patients that $25 \%$ (95\% CI $19.54 \%-30.46 \%$ ) of online self-diagnosers were reportedly persuaded by the information found online to see a health professional. This suggests the proportion of people encouraged to seek medical help based on Web use for symptom appraisal may be significantly lower among colorectal cancer patients than in the general population surveyed by Fox and Duggan [1].

Using logistic regression with a survey sample of more than 2000 Americans aged 12 years and older, Ybarra et al [47] found that online self-diagnosers were 2.5 times more likely to report contacting a health professional than online health information seekers who did not try to diagnose symptoms online, suggesting Web use for symptom appraisal is linked to increased health care contact.

Some studies suggest that the mode of presenting information on a website may affect users' decisions to seek medical advice: in a UK-based qualitative study [24], participants reportedly felt encouraged to seek help after viewing an online "digital storytelling" video about urogenital atrophy; $73 \%$ who had reportedly been too embarrassed to see a health professional before and $87 \%$ who had not wanted to bother their doctor would now seek help. In an online pilot randomized trial, Mueller et al [33] examined whether addition of theory-based components to online health information can increase intention to seek help. The theory-based components appeared to significantly increase 
intention to seek medical help, although the sample size in this pilot study ( $\mathrm{N}=97)$ was too small to allow firm conclusions.

Using log-based search engine data, White and Horvitz [44] examined search behaviors related to health care utilization intent. Health care utilization intent was assumed to be present when users conducted searches for health care practitioners/clinics near their geographical area. They found that users who displayed certain search behavior-such as visiting websites that mention serious conditions before benign ones-were more likely to show health care utilization intent subsequently. This suggests online search behavior following symptom queries is related to subsequent health care contact, although mechanisms of causality are unclear based on this data. Furthermore, the authors do not report whether/how their algorithms were validated; thus, it is unclear whether their proxy measure of health care utilization intent is valid.

By observing how patients attending a rheumatology clinic completed the NHS and WebMD symptom-checker tools, Powley et al [38] found indications that symptom-checker tools provide information that can propagate unnecessary help seeking. Of 34 patients, 15 were inappropriately advised to seek help from emergency services rather than primary care, indicating potential issues with the algorithms used in symptom-checker tools. One should bear in mind, however, that this study does not allow any conclusion on whether real users would follow this advice or not.

\section{Theme 2: Decreased Help Seeking}

In Powell et al's [37] interview study of users $(\mathrm{N}=26)$ of the NHS Direct website (the official website of the UK National Health Service), some participants reportedly used online health information as a form of "demand management," to identify trivial symptoms not warranting medical attention. Similarly, some participants in Fiksdal et al's [26] focus group study reported using the Web to avoid "bothering" health professionals with trivial symptoms. In both studies, it was not followed up whether users had correctly or incorrectly classified symptoms as trivial. Finally, in Attfield et al's [6] interview study, participants reported sometimes being reassured by Web searches that help seeking was not necessary. Evidence for this theme stems only from qualitative studies, thus, generalizability is uncertain.

\section{Theme 3: Communication with Health Professionals}

Fox and Duggan [1] found that 53\% of online self-diagnosers reportedly discussed the health information found online with a health professional. Two qualitative studies by Cooper et al [23] and Attfield et al [6] found that patients used the Web to appraise symptoms in order to prepare for consultations by preparing questions, collating relevant information, and enhancing their knowledge in order to understand the advice received.

Two studies found indications that Web use for symptom appraisal is related to reduced communication with a health professional [27,41]. Hay et al [27] found that new rheumatology patients who engaged in Web use for symptom appraisal were significantly less likely to want to challenge their health professionals' advice than those who did not. The authors note that study participants were concerned about evoking the impression of questioning health professionals' advice. Thomson et al [41] found that Web use for symptom appraisal was significantly related to feeling hesitant about discussing symptoms with a health professional. However, direction of causality is unclear. It is possible that information found online dissuaded individuals from communicating with health professionals or that people chose to research symptoms online because they were reticent about discussing their symptoms.

From the preceding findings, we can conclude that Web use for symptom appraisal is used to inform the decision of whether to present to health services and that online self-diagnosers are more likely than other health information seekers to contact a health professional. This can potentially be increased, where appropriate, with novel methods such as "digital storytelling" or theory-based components. Some evidence also suggests that online health information can potentially reduce help seeking by calming users' fears. It is unclear, however, what proportion of users feel encouraged or discouraged to seek help appropriately (ie, what proportion of users who feel encouraged to seek help actually have a condition warranting medical attention, and what proportion of users who feel discouraged to seek help actually do not need medical attention). Furthermore, it is unclear whether those engaging in Web use for symptom appraisal are more or less likely to seek medical advice than those experiencing the same symptoms without researching online because this comparison was not made in any of the included studies. Web use for symptom appraisal can also play a role in communication with health professionals by influencing how individuals prepare for consultations and prompting discussion of online health information.

\section{Emotional Consequences of Web Use for Symptom Appraisal}

In White and Horvitz's [42] survey among 515 Microsoft employees, $38.5 \%$ reported that online health information had made them feel anxious in the past, and $50.3 \%$ reported Web use for symptom appraisal had made them feel less anxious. The survey sample was biased toward younger, more educated, and information technology-literate respondents.

Powell et al [37], who examined the motivations of users of the NHS Direct website using semistructured interviews, found that participants sought health information online to obtain reassurance about symptoms. The majority nevertheless subsequently sought medical help, although sometimes with less urgency and anxiety.

Teriaky et al [40] surveyed patients ( $N=87)$ awaiting appointments at a general gastroenterology clinic and asked those who reported using the Web prior to their consultations whether this had changed their anxiety levels. In all, 77\% experienced no change, $21 \%$ experienced an increase, and $2 \%$ a decrease. One should note that this sample consists of those who decided to report to health services (and who admitted Web use for symptom appraisal); there may be a larger proportion of users who felt calmed by their searches and therefore did not present to health services. 
Lauckner et al [29] found in their experimental laboratory-based study $(\mathrm{N}=274)$ that presenting search engine results relating to serious conditions before benign conditions and a higher frequency of results relating to serious conditions was related to negative emotional outcomes such as fear. These findings suggest a causal relationship between exposure to search results during Web use for symptom appraisal and increases in anxiety.

Another experimental study conducted by Norr et al [34], however, found no difference in the anxiety levels of their participants $(\mathrm{N}=56)$ following review of either (1) websites containing information on causes of symptoms or (2) websites on general health and wellness (eg, exercise, healthy diet) without reference to medical conditions or symptoms.

Therefore, some evidence suggests there is a relationship between Web use for symptom appraisal and health anxiety. Findings from experimental studies were mixed regarding causal relationships.Surveys and interviews indicate there is a potential for calming effects and decreases in anxiety, and that the proportion who report feeling calmed by Web use for symptom appraisal is higher than those reporting anxiety. It is also possible that those who engage in Web use for symptom appraisal are more anxious about their health generally. It is unclear when anxiety is warranted because participants' actual diagnoses were not followed up, and comparisons to those who did not research symptoms was lacking.

\section{Discussion}

This is the first systematic review and synthesis of the literature available on Web use for symptom appraisal. Our main findings were:

1. Approximately $35 \%$ of the general population engage in Web use for symptom appraisal, but the proportion can vary considerably (25\%-75\%) depending on the population under study.

2. Symptoms tend to be researched online when they are long term, potentially embarrassing/stigmatized, have been presented to health services previously with inconclusive outcomes, and/or when they are perceived as trivial.

3. Searches tend to be based on symptoms rather than hypothesized conditions; users seem to focus on particular symptoms while disregarding other symptoms and aspects such as frequency and duration.

4. Once a selection of results is returned by the search tool, people use specific techniques to narrow results down (eg, taking into account the position on the results page or the credibility of the source)

5. Evidence indicates that online information is used to inform the decision of whether to contact health services and is related to (increased and decreased) anxiety, but the precise impact cannot be discerned due to lack of follow-up and appropriate comparison groups.

Subsequently, we discuss whether Web use for symptom appraisal should be viewed as an asset or a liability in health care delivery based on currently available evidence, and make recommendations for the improvement of online health information.

\section{Web Use for Symptom Appraisal: Assistance or Hindrance to Health Promotion?}

Criticisms of online self-diagnoses include concern over unnecessary anxiety and health care utilization [5,49]. Our review confirms that the Web can increase anxiety and health care contact among users $[5,29,42,44]$, but reveals that there is insufficient evidence to conclude this occurs unnecessarily.

First, it is important to note limitations of approaches used to examine relationships between Web use for symptom appraisal and health anxiety or help-seeking behavior. Cross-sectional surveys cannot show direction of causality. It is possible that using the Web to appraise symptoms causes anxiety, or that anxiety triggers Web use for symptom appraisal, or that a third factor influences both. Furthermore, the surveys that reported on anxiety among online self-diagnosers were biased toward certain demographic [42] or patient groups [40], and did not use validated measures of anxiety levels.

Log-based studies, which evaluate behavior based on search engine log data, do not allow firm conclusions regarding users' actual behaviors and motivations. For example, White and Horvitz [5] found that users who begin their searches for symptoms often progress to researching serious conditions, but it is not clear whether users are anxious or using the information to reassure themselves. The authors assume certain search terms signal certain intentions (eg, a symptom and the term "cause" signals diagnostic intent), but no action was described to determine the validity of these assumptions. Thus, insights from log-based studies are limited.

Experimental research shows that users asked to research certain symptoms may report feeling anxious following Web searches [29], but it is not possible to infer whether this anxiety would be unwarranted in a naturalistic setting (ie, if symptoms were actually present).

Using the Web to appraise symptoms may also decrease anxiety in some cases $[37,42]$ and Web searches are sometimes used to identify alternatives to health care utilization $[6,37]$. Individuals describe using online information to evaluate mild/superficial symptoms to avoid wasting health professionals' time [26]. This shows that Web use for symptom appraisal can also decrease anxiety and help seeking. It is possible that Web use for symptom appraisal discourages help seeking for trivial symptoms, thus reducing pressure on health care resources. However, it is also possible that Web use for symptom appraisal leads to complacency and prevents help seeking when it is actually necessary.

There are also indications that Web-based information can help individuals recognize their symptoms as signs of serious conditions [41]. Indeed, our review highlights that online health information is an important resource when obtaining information from health professionals is difficult (eg, when symptoms are embarrassing or stigmatized) $[25,39,41]$ or when previous visits to health care have been ineffective $[27,35]$. This suggests there is potential for the Web to be an assistance to health care.

Finally, it should be noted that worry can also have positive effects on health behaviors [50]. The Protection Motivation Theory suggests that fear will increase intention to perform a 
certain behavior if the individual feels able to perform the behavior and believes that the behavior will reduce the threat [51]. Similarly, according to the Health Belief Model, fear should result in recommended health behavior if perceived benefits of the recommended behavior are high and barriers are low [51]. Overall, this indicates anxiety induced through online health information can enhance recommended health behaviors if information is presented in a way that enables concrete action and decision making.

A limitation we discovered across different methodologies was the lack of follow-up on participants' help-seeking behavior and diagnoses. Without this information, we cannot discern whether individuals' self-diagnoses and decisions regarding help-seeking behavior are appropriate or not. We also cannot determine long-term impacts on health care utilization. Furthermore, essential comparison groups are generally lacking. For example, it would be necessary to compare those who research symptoms online with those who do not (rather than surveying only online self-diagnosers), and to compare those who present to health services with those who do not (rather than surveying only patients presenting in clinic) to determine impacts of Web use.

\section{Recommendations to Improve Online Health Information}

Based on the findings of this review, we suggest changes to health websites, Web apps, and search engines such that they can provide useful information to those researching symptoms.

Our analyses reveal that users tend to search inductively based on symptoms. Search engines and symptom-checker tools need to ensure users are directed to useful information when symptoms are entered. The review also shows that searchers tend to omit dimensions such as duration and frequency of symptoms in their search terms [28], and that symptom-based searchers struggle to find relevant results due to lack of specificity of their search terms. This suggests it is important that users are directed to useful terms to narrow their search and prompted to provide information on duration and frequency of symptoms to improve specificity of searches. In support of this, recent research suggests that incorporation of query expansion techniques into information retrieval systems can improve the search effectiveness of search engines for diagnostic symptom searches [52].

Our review also reveals that online health information can impact on the decision to seek help and on communication with health professionals. Health websites and apps need to ensure they provide useful information to support searchers in their decisions and health care interactions. Health websites providing symptom information should, for example, provide clear guidelines on when medical advice should be sought (eg, if a symptom has a certain quality or duration) and how help should be sought (eg, immediately via emergency services or within the next week via primary care).

\section{Strengths and Limitations}

As the review includes a diversity of study types and methods, a quantitative synthesis or meta-analysis was not possible. However, traditional forms of systematic review that do not make use of all forms of evidence often do not take differing contexts into account, limiting their use to policy makers and practitioners [15]. More inclusive forms of review that combine findings from different study designs allow a richer, more holistic understanding of the phenomenon under study [15]. We were able to combine real-world insights from observational studies, such as analyses of search engine log data with data from more controlled, experimental settings, thereby improving external and internal validity. Furthermore, by incorporating findings from large, population-based studies as well as smaller interview-based studies, we were able to gain an understanding of the impact of Web use for symptom appraisal at the population level, while also obtaining more detailed reports of peoples' perceptions and experiences. Moreover, by including studies that cover a broad range of populations (eg, different conditions/symptom profiles, age groups, socioeconomic status), we have shown how Web usage can differ depending on context.

In this review, we considered a diversity of symptoms and conditions; when more research in this area becomes available, it would be useful to carry out more focused reviews because the nature of the symptom is likely to influence Web use online [25-27,35,39,41].

Finally, it should also be noted that this review did not examine Web use for mental health symptoms. Web use for symptoms related to mental health and its impact on help seeking represent an important field of study and should be assessed in a separate review of the literature.

\section{Conclusions and Future Work}

This systematic review indicates that the Web can disseminate information to those worried about symptoms and can affect their decisions to present to health services. It also suggests Web use for symptom appraisal can impact on how patients prepare for consultations with health care professionals. Thus, we can conclude that Web use for symptom appraisal has the potential to influence the timing of help seeking and the communication between patients and health care professionals during consultations.

At present, limitations of the reviewed studies mean it is not clear when the Web plays a beneficial role in health care delivery and when it is detrimental. Web use for symptom appraisal has been linked to increased as well as decreased anxiety and health care contact. However, the evidence does not show when this is warranted because most studies did not follow up whether participants ultimately sought help following their Web searches and whether they received a diagnosis. Furthermore, comparison groups are lacking to determine the effects of Web use for symptom appraisal.

We need longitudinal research that follows up whether participants seek help and are ultimately diagnosed following Web searches, and compare Web searchers to non-Web searchers. These data can then be used to weigh the benefits of Web use for symptom appraisal (eg, reductions in delays to diagnosis and avoidance of unnecessary health care use) against the disadvantages (eg, unnecessary anxiety and health care use) and relate these to health care costs. Research should focus on real-world samples of people experiencing symptoms and could 
involve novel methods of tracking behavior, such as analysis of search engine log data and mobile geotracking as used in some of the included studies to follow people over time. These studies have the advantage of high external validity and large sample sizes. However, the algorithms used to analyze these data should first be tested extensively for reliability and validity before further work to evaluate cost effectiveness can meaningfully be conducted. Moreover, further experimental studies would allow a detailed analysis of search behavior. Future research could examine how the different search strategies identified here-symptom-based, condition-based, and treatment-based — relate to cognitive biases and link this to theory.

\section{Acknowledgments}

This project was funded by a Medical Research Council (MRC) Doctoral Training Partnership studentship (Ref: 1354978) and by a President's Doctoral Scholar Award from the University of Manchester.

\section{Conflicts of Interest}

None declared.

\section{Authors' Contributions}

JM drafted the review protocol, and all coauthors critically revised the protocol. JM, AD, and JV independently completed the study selection procedure and critically discussed all studies for inclusion in the review. JM extracted and analyzed the data and wrote the first draft of the manuscript. CT, SH, and CJ contributed to discussion of the content and analysis method. All coauthors reviewed and edited the manuscript before submission.

\section{Multimedia Appendix 1}

Example search strategy.

[PDF File (Adobe PDF File), 18KB-Multimedia Appendix 1]

\section{Multimedia Appendix 2}

Data extraction sheet.

[PDF File (Adobe PDF File), 24KB-Multimedia Appendix 2]

\section{Multimedia Appendix 3}

Quality appraisal of included studies.

[PDF File (Adobe PDF File), 103KB-Multimedia Appendix 3]

\section{Multimedia Appendix 4}

NVivo Matrix Screenshot.

[PNG File, 191KB-Multimedia Appendix 4]

\section{References}

1. Fox S, Duggan M. Pew Research Center. 2013 Jan 15. Health online 2013 URL: http://pewinternet.org/Reports/2013/ Health-online.aspx [accessed 2016-07-08] [WebCite Cache ID 6iqsuJyWn]

2. Andreassen HK, Bujnowska-Fedak MM, Chronaki CE, Dumitru RC, Pudule I, Santana S, et al. European citizens' use of E-health services: a study of seven countries. BMC Public Health 2007;7:53 [FREE Full text] [doi: 10.1186/1471-2458-7-53] [Medline: 17425798 ]

3. Dickerson SS, Reinhart A, Boemhke M, Akhu-Zaheya L. Cancer as a problem to be solved: internet use and provider communication by men with cancer. Comput Inform Nurs 2011 Jul;29(7):388-395. [doi: 10.1097/NCN.0b013e3181f9ddb1] [Medline: 20975535]

4. Kirschning S, von Kardorff E. The use of the Internet by women with breast cancer and men with prostate cancer-results of online research. J Public Health 2007 Jul 10;16(2):133-143. [doi: 10.1007/s10389-007-0134-0]

5. White RW, Horvitz E. Cyberchondria. ACM Trans Inf Syst 2009 Nov 01;27(4):1-37. [doi: 10.1145/1629096.1629101]

6. Attfield SJ, Adams A, Blandford A. Patient information needs: pre- and post-consultation. Health Informatics J 2006 Jun;12(2):165-177. [doi: 10.1177/1460458206063811] [Medline: 17023406]

7. Radzikowska E, Roszkowski-Śliż K, Głaz P. The impact of timeliness of care on survival in non-small cell lung cancer patients. Pneumonol Alergol Pol 2012;80(5):422-429 [FREE Full text] [Medline: 22926903] 
8. Duprez D. Early detection of cardiovascular disease-the future of cardiology? E-J ESC Counc Cardiol Pract 2006;4(19):1 [FREE Full text]

9. Topouzis F, Anastasopoulos E. Glaucoma-the importance of early detection and early treatment. Eur Ophthalmic Rev 2007;13(4):16. [doi: 10.17925/EOR.2007.00.00.13]

10. Centre for Reviews and Dissemination. CRD's Guidance for Undertaking Reviews in Health Care. York: Centre for Reviews and Dissemination, University of York; 2009.

11. Liberati A, Altman DG, Tetzlaff J, Mulrow C, Gøtzsche PC, Ioannidis JP, et al. The PRISMA statement for reporting systematic reviews and meta-analyses of studies that evaluate healthcare interventions: explanation and elaboration. BMJ 2009;339:b2700 [FREE Full text] [Medline: 19622552]

12. eBiz. 2016. Top 15 most popular search engines URL: http://www.ebizmba.com/articles/search-engines [accessed 2016-07-13] [WebCite Cache ID 6iyL0tgeK]

13. Dixon-Woods M, Cavers D, Agarwal S, Annandale E, Arthur A, Harvey J, et al. Conducting a critical interpretive synthesis of the literature on access to healthcare by vulnerable groups. BMC Med Res Methodol 2006;6:35 [FREE Full text] [doi: 10.1186/1471-2288-6-35] [Medline: 16872487]

14. Mays N, Pope C, Popay J. Systematically reviewing qualitative and quantitative evidence to inform management and policy-making in the health field. J Health Serv Res Policy 2005 Jul;10 Suppl 1:6-20. [doi: 10.1258/1355819054308576] [Medline: 16053580]

15. Dixon-Woods M, Agarwal S, Jones D, Young B, Sutton A. Synthesising qualitative and quantitative evidence: a review of possible methods. J Health Serv Res Policy 2005 Jan;10(1):45-53. [Medline: 15667704]

16. Braun V, Clarke V. Using thematic analysis in psychology. Qual Res Psychol 2006 Jan;3(2):77-101. [doi: 10.1191/1478088706qp063oa]

17. Spencer L, Ritchie J, O'Connor W, Morrell G, Ormston R. Analysis in practice. In: Qualitative Research Practice: A Guide For Social Science Students and Researchers. London: Sage Publications; 2013:295-346.

18. Brown LD, Cai TT, Dasgupta A. Interval estimation for a binomial proportion. Stat Sci 2001;16(2):101-133 [FREE Full text]

19. Briet JP, Hageman MG, Blok R, Ring D. When do patients with hand illness seek online health consultations and what do they ask? Clin Orthop Relat Res 2014 Apr;472(4):1246-1250 [FREE Full text] [doi: 10.1007/s11999-014-3461-9] [Medline: 24442841]

20. Cartright M, White R, Horvitz E. Intentions and attention in exploratory health search. In: Proceedings of the 34th international ACM SIGIR conference on Research and development in Information Retrieval. 2011 Presented at: SIGIR '11; Jul 24-28, 2011; Beijing, China p. 65-74. [doi: 10.1145/2009916.2009929]

21. Chin J, Fu W, Kannampallil T. Adaptive information search: age-dependent interactions between cognitive profiles and strategies. In: Proceedings of the SIGCHI Conference on Human Factors in Computing Systems. 2009 Presented at: CHI '09; Apr 4-9, 2009; Boston, MA p. 1683-1692. [doi: 10.1145/1518701.1518961]

22. Chin J, FU WT. Interactive effects of age and interface differences on search strategies and performance. In: Proceedings of the SIGCHI Conference on Human Factors in Computing Systems. 2010 Presented at: CHI '10; Apr 10-15, 2010; Atlanta, GA p. 403-412. [doi: 10.1145/1753326.1753387]

23. Cooper CP, Polonec L, Stewart SL, Gelb CA. Gynaecologic cancer symptom awareness, concern and care seeking among US women: a multi-site qualitative study. Fam Pract 2013 Feb;30(1):96-104 [FREE Full text] [doi: 10.1093/fampra/cms040] [Medline: 22948336]

24. Cumming G, Currie H, Moncur R, Lee A. Web-based survey on the effect of digital storytelling on empowering women to seek help for urogenital atrophy. Menopause Int 2010;16(2):51-55. [Medline: 20729493]

25. De Choudhury M, Ringel Morris M, White RW. Seeking and sharing health information online: comparing search engines and social media. 2014 Presented at: SIGCHI Conf Hum Factors Comput Syst; Apr 26-May 1, 2014; Toronto, ON. [doi: $10.1145 / 2556288.2557214]$

26. Fiksdal AS, Kumbamu A, Jadhav AS, Cocos C, Nelsen LA, Pathak J, et al. Evaluating the process of online health information searching: a qualitative approach to exploring consumer perspectives. J Med Internet Res 2014;16(10):e224 [FREE Full text] [doi: 10.2196/jmir.3341] [Medline: 25348028]

27. Hay MC, Cadigan RJ, Khanna D, Strathmann C, Lieber E, Altman R, et al. Prepared patients: internet information seeking by new rheumatology patients. Arthritis Rheum 2008 Apr 15;59(4):575-582. [doi: 10.1002/art.23533] [Medline: 18383399]

28. Keselman A, Browne AC, Kaufman DR. Consumer health information seeking as hypothesis testing. J Am Med Inform Assoc 2008;15(4):484-495 [FREE Full text] [doi: 10.1197/jamia.M2449] [Medline: 18436912]

29. Lauckner C, Hsieh G. The presentation of health-related search results and its impact on negative emotional outcomes. In: Proceedings of the SIGCHI Conference on Human Factors in Computing Systems. 2013 Presented at: CHI '13; Apr 27-May 2, 2013; Paris p. 333-342. [doi: 10.1145/2470654.2470702]

30. Luger TM, Houston TK, Suls J. Older adult experience of online diagnosis: results from a scenario-based think-aloud protocol. J Med Internet Res 2014 Jan 16;16(1):e16 [FREE Full text] [doi: 10.2196/jmir.2924] [Medline: 24434479]

31. Medlock S, Eslami S, Askari M, Arts DL, Sent D, de Rooij SE, et al. Health information-seeking behavior of seniors who use the Internet: a survey. J Med Internet Res 2015;17(1):e10 [FREE Full text] [doi: 10.2196/jmir.3749] [Medline: 25574815] 
32. Morgan T, Schmidt J, Haakonsen C, Lewis J, Della RM, Morrison S, et al. Using the internet to seek information about genetic and rare diseases: a case study comparing data from 2006 and 2011. JMIR Res Protoc 2014 Feb 24;3(1):e10 [FREE Full text] [doi: 10.2196/resprot.2916] [Medline: 24565858]

33. Mueller J, Davies A, Harper S, Jay C, Todd C. Widening access to online health education for lung cancer. In: Proceedings of the 13th Web for All Conference. 2016 Presented at: W4A '16; Apr 11-13, 2016; Montreal, QC p. 35. [doi: $10.1145 / 2899475.2899495]$

34. Norr AM, Capron DW, Schmidt NB. Medical information seeking: impact on risk for anxiety psychopathology. J Behav Ther Exp Psychiatry 2014 Sep;45(3):402-407. [doi: 10.1016/j.jbtep.2014.04.003] [Medline: 24818986]

35. North F, Varkey P, Laing B, Cha SS, Tulledge-Scheitel S. Are e-health web users looking for different symptom information than callers to triage centers? Telemed J E Health 2011;17(1):19-24. [doi: 10.1089/tmj.2010.0120] [Medline: 21214306]

36. Perez SL, Paterniti DA, Wilson M, Bell RA, Chan MS, Villareal CC, et al. Characterizing the processes for navigating Internet health information using real-time observations: a mixed-methods approach. J Med Internet Res 2015;17(7):e173 [FREE Full text] [doi: 10.2196/jmir.3945] [Medline: 26194787]

37. Powell J, Inglis N, Ronnie J, Large S. The characteristics and motivations of online health information seekers: cross-sectional survey and qualitative interview study. J Med Internet Res 2011 Feb;13(1):e20 [FREE Full text] [doi: 10.2196/jmir.1600] [Medline: 21345783]

38. Powley L, McIlroy G, Simons G, Raza K. Are online symptoms checkers useful for patients with inflammatory arthritis? BMC Musculoskelet Disord 2016 Aug;17(1):362 [FREE Full text] [doi: 10.1186/s12891-016-1189-2] [Medline: 27553253]

39. Rice RE. Influences, usage, and outcomes of Internet health information searching: multivariate results from the Pew surveys. Int J Med Inform 2006 Jan;75(1):8-28. [doi: 10.1016/j.ijmedinf.2005.07.032] [Medline: 16125453]

40. Teriaky A, Tangri V, Chande N. Use of internet resources by patients awaiting gastroenterology consultation. Turk J Gastroenterol 2015 Jan;26(1):49-52 [FREE Full text] [doi: 10.5152/tjg.2015.6043] [Medline: 25698271]

41. Thomson MD, Siminoff LA, Longo DR. Internet use for prediagnosis symptom appraisal by colorectal cancer patients. Health Educ Behav 2012;39(5):583-588 [FREE Full text] [doi: 10.1177/1090198111423941] [Medline: 21990571]

42. White RW, Horvitz E. Experiences with web search on medical concerns and self diagnosis. AMIA Annu Symp Proc 2009;2009:696-700 [FREE Full text] [Medline: 20351943]

43. White RW, Horvitz E. Predicting escalations of medical queries based on web page structure and content. In: Proceedings of the 33rd International ACM SIGIR Conference on Research and Development in Information Retrieval. 2010 Presented at: SIGIR '10; Jul 19-23, 2010; Geneva p. 769-770. [doi: 10.1145/1835449.1835607]

44. White RW, Horvitz E. Web to world: predicting transitions from self-diagnosis to the pursuit of local medical assistance in web search. AMIA Annu Symp Proc 2010:882-886 [FREE Full text] [Medline: 21347105]

45. White RW, Horvitz E. Studies of the onset and persistence of medical concerns in search logs. In: Proceedings of the 35 th International ACM SIGIR Conference on Research and Development in Information Retrieval. 2012 Presented at: SIGIR '12; Aug 12-16, 2012; Portland, OR p. 265-274. [doi: 10.1145/2348283.2348322]

46. White RW, Horvitz E. Captions and biases in diagnostic search. ACM Trans Web 2013 Oct 01;7(4):1-28. [doi: $10.1145 / 2486040]$

47. Ybarra ML, Suman M. Help seeking behavior and the Internet: a national survey. Int J Med Inform 2006 Jan;75(1):29-41. [doi: 10.1016/j.ijmedinf.2005.07.029] [Medline: 16129659]

48. Lewis C. Using the "Thinking Aloud" Method in Cognitive Interface Design. Yorktown Heights, NY: IBM TJ Watson Research Center; 1982.

49. White RW, Horvitz E. From web search to healthcare utilization: privacy-sensitive studies from mobile data. J Am Med Inform Assoc 2013 Jan 1;20(1):61-68 [FREE Full text] [doi: 10.1136/amiajnl-2011-000765] [Medline: 22661560]

50. Chae J. Online cancer information seeking increases cancer worry. Comput Hum Behav 2015 Nov;52(C):144-150. [doi: 10.1016/j.chb.2015.05.019]

51. Conner M, Norman P. Predicting and Changing Health Behaviour: Research and Practice with Social Cognition Models. Berkshire, UK: Open University Press; 2015.

52. Palotti J, Zuccon G, Goeuriot L, Kelly L, Hanbury A, Jones G. CLEF eHealth Evaluation Lab 2015, Task 2: Retrieving Information About Medical Symptoms. 2015. URL: http://ceur-ws.org/Vol-1391/inv-pap9-CR.pdf [accessed 2017-05-28] [WebCite Cache ID 6qnp2RoKL]

\section{Abbreviations \\ PRISMA: Preferred Reporting Items for Systematic Reviews and Meta-Analyses}


Edited by G Eysenbach; submitted 06.10.16; peer-reviewed by A Marcu, CJ Lee; comments to author 22.01.17; revised version received 06.03.17; accepted 23.03.17; published 13.06.17

Please cite as:

Mueller J, Jay C, Harper S, Davies A, Vega J, Todd C

Web Use for Symptom Appraisal of Physical Health Conditions: A Systematic Review

$J$ Med Internet Res 2017;19(6):e202

URL: http://www.jmir.org/2017/6/e202/

doi: 10.2196/jmir.6755

PMID: 28611017

(CJulia Mueller, Caroline Jay, Simon Harper, Alan Davies, Julio Vega, Chris Todd. Originally published in the Journal of Medical Internet Research (http://www.jmir.org), 13.06.2017. This is an open-access article distributed under the terms of the Creative Commons Attribution License (https://creativecommons.org/licenses/by/4.0/), which permits unrestricted use, distribution, and reproduction in any medium, provided the original work, first published in the Journal of Medical Internet Research, is properly cited. The complete bibliographic information, a link to the original publication on http://www.jmir.org/, as well as this copyright and license information must be included. 